\title{
FINANCIAL INCLUSION AND GENDER BARRIERS FOR RURAL WOMEN
}

\author{
Arpita Manta \\ Assistant Professor, Department of Management, \\ Barpeta Girls’ College, Barpeta, Assam, India
}

\begin{abstract}
This paper tries to examine the gendered nature of barriers faced by rural women which intersects financial inclusion worldwide. Although financial inclusion for rural women has been linked with poverty eradication and economic empowerment, the delivery of financial products and services to rural women has been at a disadvantageous position. Some of the barriers women experience in accessing financial resources are embedded in the patriarchal bias of the society.

Gender related barriers are those barriers that are specific to women which arise due to discrimination and societal norms. Gender related barriers that inhibit women's ability to access to financial services and block women empowerment should be considered carefully while preparing these programs. A feminist analysis was done to understand the causes of gender related barriers and measures adopted worldwide to devise innovative strategies.

Gender-transformative approaches to financial inclusion go beyond focussing on access to financial services to challenging the existing gender inequalities that impede women's financial inclusion and economic empowerment.

Keywords: Barriers, discrimination, patriarchy, gender, feminist analysis

Cite this Article: Arpita Manta, Financial Inclusion and Gender Barriers for Rural Women, International Journal of Management, 10 (5), 2019, pp. 61-72.

http://iaeme.com/Home/issue/IJM?Volume=10\&Issue=5
\end{abstract}

\section{INTRODUCTION}

Financial inclusion is an important element in the formulation of Sustainable development goals (SDGs)[1], the successor of Millennium development goals (MDGs) which gives importance to gender equality for women. Women's equal access to and control over economic and financial resources is critical for the achievement of gender equality and empowerment of women. Advancement in financial inclusion for women requires that women have access and control over a wide range of financial products and services, delivered through effective financial institutions and having the adequate financial knowledge and skills to use those products. Rural women face multiple barriers and financial inclusion is only a part of a wider

programme addressing several limiting factors which affect women. Financial inclusion has not been able to actively address many of the structural barriers, systemic and societal barriers, 
gender biases and inequalities that rural women continue to face which prevent women from being able to start or grow a business.

Factors constraining women's access to finance are complex and includes broader social, legal and cultural factors alongside limited gender gap data on women's financial inclusion. Accelerating women's financial inclusion thus requires bold and sustained action to advance women's economic rights whereas access to a transaction account is considered to be the just the first step towards achieving financial inclusion. A gender-transformative approach to financial inclusion focuses on increasing access to appropriate financial services for women, while also challenging gender inequalities in power relations, socio-cultural norms, and regulatory frameworks.

\subsection{The importance of gender equality for financial inclusion}

Gender equality promotes equal participation of women like men into the formal financial system. Gender equality and access to economic resources are a part of basic human rights for women and their absence reflects the inferior status of women in society. Under the 2030 Agenda for Sustainable Development, Sustainable Development Goal numbered 5 speaks of "Achieving gender equality and empowering all women and girls". Access to formal financial services by women is instrumental in helping to achieve gender equality[2] and women empowerment. The goal is to ensure that women and women-led businesses have access to and are able to use multiple financial services as tools to enjoy their financial freedom which will allow them to contribute to economic growth.

More recently, Demirgüç-Kunt et al. (2015) confirmed the existence of a gender gap in financial inclusion even after controlling for a host of individual characteristics including income, education, employment status, rural residency and age.

Gender inequality is still a major constrain for financial inclusion of women. There prevails many social stigma regarding position of women in society. Their roles are closely linked to their socially defined gender roles[3], responsibilities and social structure. Women's financial inclusion can make an important contribution to women's economic and broader empowerment.

\subsection{Financial inclusion and Rural Women}

The G20 has acknowledged the important role that financial inclusion can play in development. The launch of the Global Partnership for Financial Inclusion (GPFI)[4] at the Seoul Summit in November 2010 is concerned with strategies to include a gender dimension. Increasing women's legal access to property to improve control over assets and efforts to gather sex disaggregated data has been central to the work of GPFI.

The fact that gender equality also matters for broader macro-economic goals has been emphasised by the IMF. At the W-20 Summit in September 2015[5], Christine Lagarde, Managing Director of the IMF had remarked that Christine Lagarde, managing director of the International Monetary Fund has said that women "often bear the brunt of poverty and limited access to economic opportunity, including unfavourable financial access." Thus, inequality is not just a moral issue-it is a macroeconomic issue. For growth to be more inclusive, finance has to be more inclusive. There are many reasons why women form a disproportionately large group in the world's unbanked population. Gender inequalities in employment and earnings, access to property and other assets, lack of acceptable collateral and a large representation in the informal and unpaid sector have led to a lack of women's participation in financial markets.

Women's financial exclusion is higher due to a combination of factors. Women's low level of financial literacy combined with their time constraints prevent them from having savings accounts and understanding the intricate process of applying for loans, etc. This leads financial institutions to exclude women from accessing finance as they are considered high-risk clients 
with limited resources to pay back loans and thus rural women gets trapped in the vicious circle of low income, low savings, poor access to credit and low returns on income.

Financial inclusion can be one of the effective ways for economic empowerment of women, their capacity to decision making, increasing their mobility, improvement of their health and their children's education. (Economic Commission of Africa, 2014)

\section{REVIEW OF LITERATURE}

Kempson et al. (2000) identified the range of physical and geographical barriers to financial inclusion factors that can contribute to financial exclusion for different products and individuals under certain circumstances. There are a number of 'dimensions' or 'forms' of financial exclusion that have been identified. The critical dimensions of financial exclusion include: (i) access exclusion- restriction of access through the process of risk management (by financial services providers); (ii) condition exclusion - conditions attached to financial products which make them inappropriate for the needs of some segments of population; (iii) price exclusionsome people can only gain access to financial products at prices they cannot afford; (iv) marketing exclusion - some people are effectively excluded by targeted marketing and sales; and (v) self-exclusion - people decide not to opt for a financial product because of the fear of refusal to access by the service providers.

A toolkit for promoting financial inclusion among rural women was designed by the govt. of United Kingdom which enumerates many steps for designing a women's financial inclusion programme. It is seen that financial exclusion of women differ from that of men. Financial inclusion must be enforced as a subset of a wider concept which is gender equality. As women face multiple barriers ${ }_{2}^{-}$- economic, social, institutional etc. during advancement in life, financial inclusion programmes can nevertheless play a vital role in improving their lives. An effective financial inclusion programme should consider different aspects of women's financial needs as well as the levels of exclusion and gender related discriminatory practises. Innovative and tailor-made financial products and services are the need of the day. Women's financial inclusion programmes should also include financial literacy and financial capability training to include women's economic and other rights. (U.K Aid, 2012).

Women's financial inclusion through financial literacy is necessary for their growth, development and overall empowerment. Financial Inclusion has been suggested to be an essential pre-requisite for poverty alleviation, upholding human rights and sustainable development. In a patriarchal society like India, the rights and opportunities are curbed due to lack of financial independence. Financial Inclusion as a tool can increase her personal savings, raise her income levels through entrepreneurship and micro-enterprises, using mainstream banking products and services to meet their household needs, accumulation of assets etc. Also, women face multiple levels of exclusion and discrimination. Gender related barriers thus must be carefully studied and examined in such programs women's financial inclusion cannot be over emphasized. (Deka, 2015, pp. 45-148)

Women due to gender inequality have literally made no progress in closing the gender gap regarding access to basic financial services. Although the overall number of women and men having access to basic financial services has increased, women still remain nine percentage points less likely than men regarding access to basic financial services. (UNSGSA, 2015)

Reena Agrawal (2011)10 observed that financial exclusion is a serious concern among SC, ST, OBC and women households as well as small businesses, mainly located in semi-urban and rural areas. The main Consequences of financial exclusion being financially excluded the absence of access to bank accounts and other saving opportunities result in lack of savings, low investments and lack of financial planning, then it becomes difficult in gaining access to credit 
getting credit from informal sources at exorbitant rates results in increased unemployment due to lack of self - employment opportunities as well as higher incidence of crime etc.

\section{RESEARCH METHODOLOGY}

The study attempts to do a feminist research taking of women and gender as the focus of analysis. Its objectives include both the construction of new knowledge and the production of social change. A feminist research[6] has been advocated to be not just on women but for women and wherever possible, with women. Also, a descriptive study was done to understand the different barriers that affect rural women.

\subsection{Research question}

How does gender dimension affect financial inclusion programmes?

\subsection{Data collection}

Secondary data was used from other published literature like World Bank report (Findex), CGAP report, Commonwealth report, reputed journals etc.

\section{OBJECTIVES}

- To assess the nature of financial inclusion of rural women in a patriarchal society.

- To study the various dimensions of gender related barriers faced by rural women in accessing and usage of financial products and services.

\subsection{Objective I}

According to the human rights argument, women should enjoy equal access to financial services so that they have equal participation in social and economic activities. Women constitute 50 percent of the world population and their exclusion would be detrimental to equitable economic growth. Some of the challenges rural women experience in accessing financial resources are embedded in the deeply entrenched patriarchal bias prevalent in the society. Patriarchy literally means rule of the father in a male-dominated family. It is a social and ideological construct which considers men (who are the patriarchs) as superior to women. Sylvia Walby in "Theorizing Patriarchy "calls it "a system of social structures and practices, in which men dominate, oppress and exploit women" (Walby,1990). As a result of patriarchy rural women are subjected to asymmetrical power relations within the family from an early age. In later life, this spills over to the community and society and restricts their access to resources and opportunities. This is particularly so with respect to their low level of financial knowledge and skills (compared to men) that deny them access to finance and leaves them at the periphery of the financial system, economically weak and trapped in the vicious circle of low investment, low income and low returns.

Patriarchy is based on a system of power relations which are hierarchal and unequal where men control women's production, reproduction and sexuality. Women's status is entrenched in the patriarchal bias of society, which confines them to a marginalised position at the bottom of the economic, social and political hierarchy. These characteristics are linked to their limited access to education, employment, entrepreneurship and formal financial markets. Moreover different social norms and legal treatment towards men and women reduce women's financial well being and limit the extent to which they can improve their knowledge, confidence and skills about economic and financial matters. Women's unequal access to finance is therefore a reflection of their subordinate status within the family and society at large.

The World Bank's Global Findex Report[7] for 2014 says that 58 per cent of women worldwide had an account, compared to 65 per cent of men, up from 47 per cent of women and 
54 per cent of men in 2011. This means that globally there is a persistent gender gap of 7 percentage points in account ownership. According to Global Financial Inclusion Database (Global Findex), globally rural women fare worse than rural men and urban women and men against key Millennium Development Goal (MDG) indicators which point to existing gender gaps in the use of financial services. As per the new data from the Global Financial Inclusion (Global Findex) database, in developing economies women are 20 percent less likely than men to have an account at a formal financial institution and 17 percent less likely to have borrowed formally in the past year. The gender gap has resulted in 1.3 billion women worldwide to remain out of the formal financial system. In terms of account ownership, 47 percent of women, own or co-own an account and 55 percent of men world- wide have an account at a formal financial institution - a bank, credit union, cooperative, post office, or microfinance institution. But in the developing countries, women are $28 \%$ less likely to haven account at formal financial institution. Also a large percentage of women cite indirect access through a family member as a reason for not having an account which can be interpreted as another manifestation of the gender gap. The database says that the gender gap is just not due to differences in income and education but exists even after women opening bank accounts.

Thus, it is imperative that organizations working on women's financial inclusion understand the social norms that limit women's access to and use of financial services and the degree to which these norms can be shifted to achieve development goals.

\subsection{Objective II}

\subsubsection{Economic barriers}

Financial inclusion is strongly linked with income generating activities of women. Gender inequalities in economic activities can adversely affect women's financial inclusion. Some of the major causes of economic barriers which rural women face are-

\section{(i) Irregular savings}

Women seek savings vehicles, and use personal savings to invest in their businesses (Aldana and Boyd, 2015). Women's ability to save has effects on other aspects of their lives, as evidence shows that savings can positively impact women's empowerment (Holloway, et al. 2017). Studies also show that even poor women are eager to save if given appealing interest rates, conveniently located financial facilities, and flexible accounts. (Morduch, J., 1999)

\section{(ii) Lack of credit facilities}

Studies have revealed that most women lack acceptable collateral security such as title deeds required by most financial institutions. Lack of collateral is further compounded by traditional property rights which are skewed against women particularly in rural areas. Lack of collateral and credit history negatively affect women's ability to secure formal and affordable credit. Women have difficulties in providing immoveable collateral, the traditional form of loan collateral, often due to existing land and property right regimes and cultural norms that discriminate against them.

\section{(iii) No control over economic and financial resources}

Gender differences in asset ownership and control can hinder women's financial inclusion. Access to financial products and services is believed to be a key enabler of women's economic empowerment, allowing them the freedom to better manage their lives. To address ownership norms that disproportionately exclude women, innovative credit technologies, such as psychometric tests, are being introduced to lenders to predict the ability of a borrower to repay a loan and reduce the need for collateral. 
In Uganda, where underlying norms dictate that women should not work outside of the home, Care[8] has introduced a series of interventions that directly addresses this constraint. The program introduced a mobile wallet to help women practice mental stock taking around the use of their finances with sub-wallets earmarked for different uses. The program also introduced dialogue between men and women around intra-household resource management and the role of women in the paid economy.

\subsubsection{Physical barriers}

\section{(i) No bank accounts}

Women who have access to bank accounts, savings mechanisms, and other financial services may be better able to control their earnings and undertake personal and productive expenditures (Islam et al., 2014). They may also be able to make more choices about how they use their time, whether for employment, leisure, income-generating activities, or education (Aker et al., 2016). They may have more substantive autonomy over their lives in decisions ranging from employment and marriage to whether to use contraception (Holloway et al., 2017). They may be better able to grow their businesses, to choose where and how to work and to raise their productivity and earnings and reduce their chances of being poor (Swamy, 2014). They may also have more options to leave abusive relationships and experience reduced exposure to intimate partner violence (Panda, 2014; Garikipati, 2008).

\section{(ii) Less account usage}

The 2014 and 2017 Global Findex indicates that there is an average 9\% gender gap in access to bank accounts among developing economies. The gender gap has remained unchanged since 2011 despite incredible progress in financial inclusion. The importance of usage as a better measure of financial inclusion was highlighted by Rami (2009) who observed that government programmes in India have led to inclusion of large numbers of low-income households without a proportionate increase in usage.

Similarly, a recent report by the UNCDF (2016)[9] revealed that a large majority of bank account owners in developing countries seldom use the accounts to store value, to transact, and to access credit and most of the bank accounts are either dormant or used as a mailbox. An Analysis of account status was conducted for SADC[10] countries by FinMark Trust in 2016. Despite South Africa and Mauritius being at the top regarding bank account access in the region, it is actually Botswana that leads in terms of percentage of used accounts. With 3 percent used accounts and 87 percent having dormant accounts, Zimbabwe is at the bottom of the usage ranking in the Region.

\section{(iii) No information about financial system}

Women's access to information and technology is limited. Due to lack of information about availability of formal financial products, women will normally access funds from informal sources of finance such as money lenders, loan sharks, rotating savings, friends, relatives, suppliers and shopkeepers which are usually costly. Generally, there is limited awareness of investment products among women compared to men in Zimbabwe.

\section{(iv) Branch remoteness}

Commercial banks operate only in profitable areas. Banks set their branches and offices only in those commercial areas. Therefore, people living in under-developed areas find it very difficult to go for any bank transaction in other area again and again. Hence, they don't go for any bank services. Lack of basic infrastructure roads, electricity and access to transport services makes it difficult for marginalized groups to access markets and financial services. 


\section{(v) Lack of documents}

Lack of legal identity like voter Id, driving license, birth certificates, employment identity card etc. Financial institutions have cumbersome and unfavourable conditions and procedures which most women are not able to provide namely bankable business plans, audited financial statements and cash flow projections.

\section{(vi) No network or associations}

Strong networks and associations provide rural women crucial information about products, logistics, suppliers and technology. Women are less likely to travel long distances to markets. lack of access to lucrative markets by women also remains a major challenge, which again hinders the growth of their businesses.

\section{(vii) Poor financial literacy}

Lack of financial capability and financial literacy are considered by many to be the most serious constraints to women's financial inclusion. According to Atkinson A, et al (2012), "financial literacy is a combination of awareness, knowledge, skill, attitude and behaviour necessary to make sound financial decisions and ultimately achieve individual well-being." According to ASIC (2014)[11], "financial literacy refers to a combination of financial knowledge, skills, attitudes and behaviours necessary to make sound financial decisions, based on personal circumstances, to improve financial wellbeing." lack of financial literacy can result in people making wrong choices, and becoming vulnerable to excessive financial risks.

\subsubsection{Personal or psychological barriers}

Box 1 offers an example from a partnership in Kenya led by Women's World Banking that aimed to address many psychological barriers faced by women when engaging with the banking sector.

\section{(i) Low self-esteem}

Women's SHGs[12] have historically played an important role in changing gender norms that restrict women's economic empowerment by building women's confidence, transferring knowledge, and promoting a greater sense of self-esteem. In many cases, women rank lower than men in their perceptions of opportunity, self-confidence, and fear of failure (Koellinger et al., 2007). For example, the Global Entrepreneurship Monitor (GEM) data show that across countries, early-stage female entrepreneurs tend to exhibit significantly higher fear of failure than male entrepreneurs (Minniti, 2010). The GEM dataset also estimates that subjective perceptions about one's own skills, likelihood of failure, and opportunities explain a significant portion of the gender gap in entrepreneurial activity. It was found that women are more risk averse than men and less likely to engage in competitive situations (Croson \& Gneezy, 2009). An OECD Survey[13] in 2013 shows that in many countries, women demonstrate less financial knowledge than men and are also less confident in their financial knowledge and skills.

\section{(ii) Less risk takers}

Women, especially in lower income groups, tend to be more cautious and risk averse about the amount of financing and business risk they are willing to take on. They are much more inclined to weigh these risks against potential impacts on the household should they be unable to repay loans. This tends to limit their business opportunities to less risk and quick return business such as hair salons, commodity broking and vending.

There are gendered differences in the ways men and women deal with risk and experience institutions, which can in turn translate into differences in the types of financial products that men and women prefer.

Evidence shows that women are cautious and more risk averse than their male counterparts, and that his is partly due to women's trust in institutions. For example, in their study of demand 
for weather index insurance in Bangladesh, Akter et al. (2016) find that although gendered differences in risk perceptions and risk aversion can explain some of the differences in demand for this kind of insurance, a key determinant of adoption is trust in institutions, which was found to be lower among women. The need for understanding women's risk preferences in the context of the institutions is also underscored in the paper by Arun et al. (2016), which highlights that higher levels of risk aversion among women needs to be understood in the context of whether or to what extent women can rely on institutions to mitigate the risk they are taking on, for instance, when they take out a loan. Similarly, a study by Delavallade et al. (2015) shows how different risk exposures can influence women's preferences for different types of financial products.

\subsubsection{Technological barriers}

The new alternative forms of digital finance open a new set of services, channels and value opportunities for women, both the financially excluded and the already financially included but underserved. Digital channels and innovative product designs have the potential to offer new and better value propositions for women when done holistically and considering social norms (W20 Argentina, 2018).

\section{(i) No mobile phones}

Mobile banking has accelerated the pace of financial inclusion worldwide. According to the 2014 Global Findex $12 \%$ of adults in the region use mobile money, compared to just $2 \%$ worldwide. This innovation has been instrumental in reaching those excluded from traditional banking services, particularly women.t does in South Asia, where women are 38 per-cent less likely to own a mobile phone than men (GSMA 2015). Women in low- and middle-income countries are still 33 percent less likely than men to use mobile money and 10 percent less likely to own a mobile phone.

GSMA worked with Telenor in India to address the mobile gender gap in the country by increasing the number of women users and changes linked to phone ownership by working on a project called Sampark[14]. In such a study done in July 2015 it states that women in India are $36 \%$ less likely to own a mobile phone than men. While this work did not directly address mobile banking, it aimed to influence one of the main bottlenecks that impact women's access to mobile banking namely the constraints having their own phone.

Gendered social norms also surround the use of technology more generally, and male control or intermediation of technology is often sought and accepted.

\section{(ii) No internet}

As per GSMA (2015), some 2.3 billion women do not have Internet access all over the world. India is the world's second biggest market for mobile phones, with more than one billion users yet women make up only $2 \%$ of Internet users in rural areas.

\subsubsection{Societal and cultural barriers}

Social norms are a far more complex barrier to female entrepreneurship: they induce female entrepreneurs to choose socially acceptable sectors and can shape their perceptions about what they are capable of achieving (Oxfam, 2017). These social norms negatively affect women's ability to benefit from outside economic opportunities - in turn, many women are not able to access and use financial services that would help them. Social norms refer to the rules that govern social behaviour, perceptions, and conduct. Social norms shape how people behave and how people expect others to behave. 


\section{(i) Discrimination}

Discrimination can affect women's demand for financial products and services. It can also impede their ability to save, borrow, pay or insure themselves against risk. Discrimination can also affect the demand for financial products and services among women.

\section{(ii) Mobility constraints}

Women mostly require permission from their husband which puts constraints on her free mobility ${ }^{16}$. Women face difficulties in travelling to banks, financial institutions and other services as they are distantly located. Women are often unable to travel to bank branches either due to societal constraints which portray that it might not be safe for women to travel alone. The DFID-funded ELAN RDC[15] Project in the Democratic Republic of Congo in 2018 is an example of a norm-aware project that sought to address the gender barriers of women's limited mobility and control over cash incomes through project design modifications. The project attempts to increase women's savings rates and control of their income within their existing restricted mobility by introducing improved cook-stoves and solar lamps, delivering agricultural trainings in areas that are conveniently accessible for women, and providing mobile banking facilities.

In Uganda, where underlying norms dictate that women should not work outside of the home, Care has introduced a series of interventions that directly addresses this constraint. The program introduced a mobile wallet to help women practice mental stocktaking around the use of their finances with sub wallets earmarked for different uses. The program also introduced dialogue between men and women around intra-household resource management and the role of women in the paid economy.

\section{(iii) Unpaid domestic and care work}

Domestic and care work[16] is vital to keep households functioning such as child care, caring for the elderly, cooking, cleaning etc is socially and economically essential yet invisible in economic accounting. Women provide the bulk of unpaid care work - around $75 \%$ - which frees up time for others (men) to participate in the economy. As a result of the lack of economic recognition of unpaid care work, societies undervalue this work, and government policies do not accurately reflect its costs and benefits.

Rural women suffer from lack of time because of unequal gender division of labour in unpaid productive and reproductive activities. Women tend to spend more time doing household chores and fending for the family leaving very little time to devote to the business which further curtails their potential to grow the business out of the subsistence level. Childbirth, childcare, and care for other family members impose limitations on women's ability to work outside or far from home, and reduce the hours they have available for productive work.

Surveys conducted in Tanzania reveal that rural women were more likely to report that they closed their business due to a pregnancy or needing to care for a family member (FSD Tanzania, 2012; Kenya National Bureau of Statistics, 2016).

\section{FINDINGS}

From the above study it can be said that

- The attainment of women's financial inclusion will remain elusive unless a gendered approach is adopted by regulators and financial institutions. Rural women all over the world face similar type of barriers to financial inclusion as patriarchal structures are highly prevalent in developing countries.

- Rural women represent a different market segment of the entire population with diverse features and financial needs. Thus, rural women must be served with different set of financial products and services which are homogenous with their day to day needs. 
- Employment in the formal economy and freedom from unpaid work can increase women's chances for greater inclusivity in the financial system.

\section{CONCLUSION}

It is imperative that organizations working on women's financial inclusion understand the social norms that limit women's access to and use of financial services and the degree to which these norms can be shifted to achieve development goals. This requires going beyond supplyside solutions that focus on investments in financial services providers. The focus should be to better understand the social norms at play and to devise strategies that engage a broader range of stakeholders at different levels of the market needed for more impactful change. Greater women's financial inclusion requires a more gender inclusive financial system that addresses the specific demand- and supply-side barriers women face.

\section{KEYNOTES}

1. SDGs were adopted by the UN in 2015 as a universal call to end poverty and promote gender equality by 2030 . It contains 17 goals that calls for immediate action

2 It is the equality in access to resources irrespective of gender including economic participation, decision making and opportunities

3. Gender roles are sex role based on the biology or sex of individuals, mostly determined by society.

4. GPFI is a platform for G20 states to carry forward the work of financial inclusion in 2010. It's partners are AFI, CGAP and IFC.

5. The first W20 Summit was held in Istanbul in September 2015 to do more on women's economic empowerment.

6. Feminist research differs from traditional research and it begins with the standpoints and experiences of women with an agenda for social change

7. Global Findex database was launched by the World Bank in 2011 to measure financial inclusion through supply side indicators

8. In 2017 Uganda participated in CARE's women digital sub wallet workshop. This e-wallet allows women to access formal bank accounts through mobile technology and have pre-labelled digital sub-wallets to categorise savings.

9. United Nations Capital Development Fund was founded in 1966 to help developing countries get finance flowing to the excluded.

10. SADC stands for South African Development Community

11. ASIC is an Australian government agency responsible for creating awareness about financial literacy. It states that financial literacy is a long-term behavioural change initiative.

12. SHGs have been a very successful model for women empowerment and financial inclusion. It has helped women to avail loans through SHG-Bank linkage programmes and form associations

13. OECD in 2013 conducted a survey on adult skills

14. Project Sampark in India tries to empower women by giving them mobile and mobile connectivity. It aims to remove the barriers that prevent women from using mobile phones

15. Norm aware initiatives tries to work within existing social norms to address market constraints for women. They focus on supporting women's paid work. It involves direct engagement of men, women and the community. Sampark in India is a norm aware project. 
16. Women are responsible for $75 \%$ of all unpaid care and domestic work. Unpaid work can take many forms depending on regions.

\section{REFERENCES}

[1] Akter, S., Krupnik, T. J., Rossi, F., \& Khanam, F, The Influence of Gender and Product Design on Farmers' Preferences for Weather-Indexed Crop Insurance. Global Environmental Change 38, 2016, pp 217-229.

[2] Aker, J. C., Boumnijel, R., McClelland, A., \& Tierney, N, Payment Mechanisms and AntiPoverty Programs: Evidence from a Mobile Money Cash Transfer Experiment in Niger. Economic Development and Cultural Change, 65(1), 2016, pp 1-37.

[3] Delavallade, C., Dizon, F., Hill, R. V., \& Petraud, J. P, Managing Risk with Insurance and Savings: Experimental Evidence for Male and Female Farm Managers in West Africa (IFPRI Discussion Paper 01426). Washington, DC, 2015

[4] Demirgüç-Kunt, A., Klapper, L. F., Singer, D., \& Van Oudheusden, P, The Global Findex Database 2014: Measuring Financial Inclusion Around the World (World Bank Policy Research Working Paper 7255). Washington, DC, 2015

[5] FSD Tanzania, Tanzania MSME: National baseline survey report, 2012

[6] GSMA, "Bridging the Gender Gap: Mobile Access and Usage in Low- and Middle-Income Countries." London, 2015

[7] GSMA, Women and Mobile Money: Insights from Kenya (Rep.). London: GSM Association, 2015

[8] Swamy, V, Financial Inclusion, Gender Dimension, and Economic Impact on Poor Households. World Development, 56, 2014, pp 1-15.

[9] Islam, M. S., Ahmed, M. F., \& Alam, M. S, The Role of Microcredit Program on Women Empowerment: Empirical Evidence from Rural Bangladesh. Developing Country Studies, 4(5), 2014, pp 90-97.

[10] Morduch, J, the Microfinance Promise. Journal of Economic Literature Vol. XXXVII, 1999

[11] Arun, S., Annim, S. K., \& Arun, T. G, 'Even After Access to Financial Services? Ricocheting Gender Equations. (IZA Discussion Paper 10099). Bonn, Germany: The Institute for the Study of Labour, 2016

[12] Minniti, M, Female entrepreneurship and Economic activity. The European Journal of Development Research, Vol. 22, 2010

[13] Oxfam, Fighting for the most marginalised Indians: Annual report, 2017

[14] Croson, Rachel., and Gneezy, Uri, Gender differences in Preferences. Journal of economic literature, vol 47, 2009

[15] Deka, P. P, Financial literacy and financial inclusion for women's empowerment: A study. International journal of applied research, vol. 1, 2015

[16] Agrawal, R, 100\% financial inclusion: A challenging task ahead. Bank quest, vol. 8, 2011 
[17] Walby, Sylvia, Theorizing patriarchy. Basil Blackwell ltd. 3 Cambridge centre, USA, 1990

[18] Kempson et al, Policy level response to financial exclusion in developed economies: Lessons for developing countries, 2000

[19] UK Aid, Promoting women's financial inclusion, A tool kit. U.K, 2012

[20] Ravikumar T, Measurement of Financial Inclusion Status of India, International Journal of Mechanical Engineering and Technology 9(7), 2018, pp. 354-364.

[21] Lakhwinder Kaur Dhillon and Dr. Upasana Srivastava, The Role of Various Financial Institutions and Regulatory Bodies in Financial Inclusion. Journal of Management, 5(3), 2018, pp. 69-79.

[22] Lakhwinder Kaur Dhillon and Dr. Upasana Srivastava, To Examine the Policies and Initiatives Taken by the Regulatory Bodies for Financial Inclusion. Journal of Management, 5(3), 2018, pp. 103-116. 